\title{
Monitoring risk factors of cardiovascular disease in cancer survivors
}

\author{
Authors: Ambika Kapoor, ${ }^{\mathrm{A}}$ Vineet Prakash, ${ }^{\mathrm{B}}$ Mallika Sekhar, ${ }^{\mathrm{C}}$ Diana M Greenfield, ${ }^{\mathrm{D}}$ Matthew Hatton, ${ }^{\mathrm{E}}$ \\ Michael EJ Lean, ${ }^{F}$ Pankaj Sharma ${ }^{G}$ and Thang $S$ Han $^{H}$
}

\begin{abstract}
There exist published literature for cardiovascular disease (CVD) risk monitoring in cancer survivors but the extent of monitoring in clinical oncology practice is unknown. We performed an interactive survey at a Royal College of Physicians conference ( 11 November 2016 ) attended by practitioners with an interest in late effects of cancer treatment and supplemented the survey with an audit among 32 lung cancer survivors treated at St Peter's NHS Hospital in 2012-2016. Among the practitioners, $40 \%$ reported CVD risk monitoring performed at least annually, which is compatible with European Group for Blood and Marrow Transplantation Guidelines, but $31 \%$ indicated that monitoring was never performed. In contrast, $77 \%$ felt that at least an annual assessment was required $(p<0.001)$. Corroborating these data, among the lung cancer survivors, $31 \%$ and $16 \%$ had lipids or glucose/HbA1C measured annually, and $28 \%$ and $31 \%$ had never had these tests performed since their cancer treatment. Alerting healthcare providers to review protocols may help reduce CVD after cancer treatments.
\end{abstract}

KEYWORDS: cardiometabolic risk, CVD prevention, health promotion, late effects

\section{Introduction}

In the UK, there are over two million cancer survivors ${ }^{1}$ and this figure is set to rise to 5.3 million by $2040 .{ }^{2}$ While prognosis

Authors: Afoundation year 2 doctor, Ashford and St Peter's NHS Foundation Trust, Chertsey, UK; ${ }^{\mathrm{B}}$ consultant radiologist, Ashford and St Peter's NHS Foundation Trust, Chertsey, UK; ' ${ }^{\text {Consultant }}$ haematologist, Royal Free NHS Foundation Trust, London, UK; ${ }^{D}$ Macmillan consultant nurse, Weston Park Hospital, Sheffield, UK and University of Sheffield, Sheffield, UK; ${ }^{E}$ consultant clinical oncologist, Weston Park Hospital, Sheffield, UK and University of Sheffield, Sheffield, UK; F consultant physician, Department of Nutrition, School of Medicine, University of Glasgow, Glasgow, UK; ${ }^{G}$ consultant neurologist, Institute of Cardiovascular Research, Royal Holloway, University of London, Egham, UK; ${ }^{H}$ consultant endocrinologist, Institute of Cardiovascular Research, Royal Holloway, University of London, Egham, UK and Ashford and St Peter's NHS Foundation Trust, Chertsey, UK varies by cancer type, treatments have improved such that half of all people diagnosed with cancer in 2010-2011 in England and Wales are expected to survive for 10 years or longer, compared with a quarter of people diagnosed in 1971-1972. The role of GPs is becoming increasingly more important in cancer survivorship care since within an average GP population of 10,000 patients, there are about 275 cancer survivors of at least 5 years following diagnosis. ${ }^{4}$

After progression or recurrence of cancer, cardiovascular disease (CVD) is the leading cause of death among survivors. ${ }^{5}$ Survivors from solid tumour cancers and haematological cancers both have a 1.6-1.7 times greater risk of CVD than non-cancer controls. ${ }^{6}$ Many major cancers have the same long-term, cumulative, risk factors (eg smoking, obesity, physical inactivity, low consumption of fruit and vegetables). The stress of major illness, and its treatments, may aggravate CVD risk, and certain cancer treatments can present specific cardiovascular hazards, such as weight gain and metabolic disturbances.

The 'late effect of cancer treatment' is a phenomenon observed in cancer survivors whereby secondary health complications appear months to years after radiotherapy ${ }^{7}$ and chemotherapy. ${ }^{8} \mathrm{CVD}$ emerges a few years post-treatment and the incidence is cumulative over subsequent years. ${ }^{9,10}$ In parallel to CVD, metabolic disturbances - including obesity and central fat distribution indicated by large waist circumference, hypertension, dyslipidaemia and diabetes - which may be aggravated by cancer therapies, all also develop progressively post-treatment. ${ }^{11-15}$

There are guidelines on monitoring CVD risk factors with the most recent recommendations for survivors of haematological cancer being the most comprehensive; ${ }^{16}$ previous recommendations have tended to be vague ${ }^{17-19}$ or show little information on CVD risk monitoring. ${ }^{20,21}$ Because of the complexity of late effects of cancer treatment, awareness of CVD risks among cancer survivors is low; little is known about the quality of risk monitoring and CVD-directed health promotion in cancer survivors in clinical practice. This is particularly true for the poor prognosis cancers whose small proportion of long-term survivors have largely been excluded from late effects studies. Therefore, we performed an interactive survey of healthcare providers to assess the frequency of CVD risk monitoring and discussion of CVD health promotion for cancer survivors. We supplemented this with a clinical audit of lung cancer survivors to assess the level of monitoring that 
currently occurs following treatment of the poorer prognosis cancers.

\section{Methods}

\section{Data procurement}

An interactive survey was conducted at a Royal College of Physicians conference on 11 November 2016; a mixed group of 95 healthcare providers - including consultant physicians across different specialties, GPs, physician associates and nurses with a vested interest in late effects of cancer treatments voted on ten questions: six related to the 'frequency of cardiometabolic risk monitoring for their patients', including weight, blood pressure (BP), waist circumference, lipids, glucose and smoking; three related to 'how they feel about how often these risk factors should be monitored'; and one related to 'how often they discuss CVD risk factors with their patients'. Complete questionnaires and data collected from interactive survey are shown in Table 1.

The clinical patient audit was registered and approved by the Audit Department, Ashford and St Peter's NHS Foundation Trust. Survivors of lung cancer were selected to represent a poor prognosis cancer and as a group known to have a high risk of cardiovascular late effects. ${ }^{6}$ This audit identified 66 patients diagnosed with lung cancer by the hospital multidisciplinary team in 2012; 32 of these patients were still alive in 2016. Their frequency of monitoring and the levels of plasma lipids (totaland high-density lipoprotein (HDL) cholesterol) and glucose/ HbA1C (glycated haemoglobin) performed by primary and secondary care physicians during the 2012-2016 period were obtained retrospectively from central databases and crosschecked by two doctors.

\section{Statistical analysis}

The interactive survey data were presented individually for each response to questions on CVD risk factors (weight, waist circumference, BP, lipids and glucose) followed by two composite variables; the first composite variable comprised the total number of responders to questions 1-5 (Table 1a) on 'frequency of CVD risk monitoring for their patients' $(n=453)$ and the second to questions 7-10 (Table $1 \mathrm{~b}$ ) on 'how they feel about how often these risk factors should be monitored' $(n=256)$. Each frequency of monitoring category (ie 'at least every 6 months', 'once a year', 'only occasionally' or 'never') was expressed in proportions that were obtained from the number of responders to each frequency of monitoring category divided by the total number of responders ( 453 for the first and 256 for the second composite).

From the audit data, the mean values of lipids and glucose were calculated as the sum of each of these risk factors divided by the frequency they were measured. Descriptive analysis was performed to assess the frequency and proportions of risk monitoring and Chi-squared test to assess differences between categories where indicated using SPSS statistical package v22.0 (SPSS Inc, Chicago, IL, USA).

\section{Results}

\section{Interactive survey of healthcare providers}

The questions asked in the survey and responses are documented in Table 1. Of those surveyed, $1 \%$ of healthcare providers reported they monitor waist circumference 'at least every 6 months'; 1\% 'at every clinic (at least once a year)'; $8 \%$ 'only occasionally'; and $89 \%$ reported they 'never' monitor waist circumference. These figures increased significantly $\left(\chi^{2}=112, \mathrm{p}<0.001\right)$ to $9.1 \%, 55.7 \%, 26.1 \%$ and $9.1 \%$, respectively, when healthcare providers were asked 'how often they feel waist circumference should be monitored'. Fig 1 shows that the frequency of comprehensive monitoring for all CVD risk factors (composite variable comprising weight, waist circumference, BP, lipids and glucose) by healthcare providers 'at least every 6 months' was reported by $6 \%$ of survey respondents, 'at every clinic (at least once a year)' by $34 \%$, 'only occasionally' by $29 \%$ and 'never' by $31 \%$. These figures were significantly different $\left(\chi^{2}=120, \mathrm{p}<0.001\right)$ to those seen when healthcare providers were asked how often they feel these risk factors should be monitored (17\%, 60\%, 20\% and $3 \%$, respectively).

Results for other individual risk factors are shown in Table 1. In addition to the specific monitoring, the survey also looked at how often potential health interventions might have been discussed with patients. It is notable that about $60 \%$ of

Table 1a. Frequency of monitoring of cardiovascular risk factors for cancer survivors by healthcare providers

\begin{tabular}{|c|c|c|c|c|}
\hline & \multicolumn{4}{|c|}{ Response, n (\%) } \\
\hline & $\begin{array}{l}\text { At least every } \\
6 \text { months }\end{array}$ & $\begin{array}{l}\text { At every clinic visit } \\
\text { (at least once a year) }\end{array}$ & $\begin{array}{l}\text { Only } \\
\text { occasionally }\end{array}$ & Never \\
\hline 1 How often do you measure your patients' weight? & $7(7.4)$ & $60(63.2)$ & $24(25.3)$ & $4(7.4)$ \\
\hline 2 How often do you measure your patients' waist circumference? & $1(1.1)$ & $1(1.1)$ & $7(7.7)$ & $81(89.0)$ \\
\hline 3 How often do you measure your patients' blood pressure? & $11(12.2)$ & $42(46.7)$ & $24(32.2)$ & $8(8.9)$ \\
\hline 4 How often do you measure your patients' cholesterol? & $1(1.1)$ & $28(30.8)$ & $25(27.5)$ & $37(40.7)$ \\
\hline 5 How often do you measure your patients' glucose? & $8(8.7)$ & $24(26.1)$ & $46(50.0)$ & $14(15.2)$ \\
\hline $\begin{array}{l}6 \text { When you see your patients, how often do you ask them about } \\
\text { cigarette smoking? }\end{array}$ & $7(7.9)$ & $45(50.6)$ & $27(30.3)$ & $10(11.2)$ \\
\hline $\begin{array}{l}7 \text { When you see your patients, how often do you discuss } \\
\text { cardiovascular risk factors? }\end{array}$ & $3(3.8)$ & $27(34.1)$ & $35(44.3)$ & $14(17.7)$ \\
\hline
\end{tabular}


Table 1b. How often healthcare providers think cardiovascular disease risk factors should be monitored in cancer survivors

\begin{tabular}{|c|c|c|c|c|}
\hline & \multicolumn{4}{|c|}{ Response, n (\%) } \\
\hline & $\begin{array}{l}\text { At least every } \\
6 \text { months }\end{array}$ & $\begin{array}{l}\text { At every clinic visit } \\
\text { (at least once a year) }\end{array}$ & $\begin{array}{l}\text { Only } \\
\text { occasionally }\end{array}$ & Never \\
\hline $\begin{array}{l}8 \text { How often do you feel your patients' weight and blood pressure } \\
\text { should be checked? }\end{array}$ & $19(22.4)$ & $63(74.1)$ & $3(3.5)$ & $0(0.0)$ \\
\hline $\begin{array}{l}9 \text { How often do you feel your patients' waist circumference should } \\
\text { be checked? }\end{array}$ & $8(9.1)$ & $49(55.7)$ & $23(26.1)$ & $8(9.1)$ \\
\hline $\begin{array}{l}10 \text { How often do you feel your patients' cholesterol and blood } \\
\text { glucose should be checked? }\end{array}$ & $17(20.5)$ & $41(49.4)$ & $25(30.1)$ & $0(0.0)$ \\
\hline
\end{tabular}

responders did get details of the patients' smoking habit and $40 \%$ routinely discuss CVD risk.

\section{Clinical audit of CVD risk monitoring in cancer survivors}

Of the 66 patients diagnosed with lung cancer in 2012, 32 (48.5\%) had survived to 2016 (4.7 years) and could be included in the study. The frequency of plasma lipid/glucose monitoring is documented in Table 2. The median age of the patients at diagnosis was 71.2 years (interquartile range 59.9-78.0). The mean (range) values for total cholesterol, HDL cholesterol and glucose were $4.45 \mathrm{mmol} / \mathrm{L}$ (3.80-5.29), 1.41 $\mathrm{mmol} / \mathrm{L}(1.15-1.73)$ and $5.95 \mathrm{mmol} / \mathrm{L}$ (4.97-6.73), respectively. There were 11 patients $(34.4 \%)$ with dyslipidaemia (total cholesterol $\geq 5 \mathrm{mmol} / \mathrm{L}$, HDL cholesterol $<1.03 \mathrm{mmol} / \mathrm{L}$ for men, $<1.29 \mathrm{mmol} / \mathrm{L}$ for women) and four patients (12.5\%) with hyperglycaemia (fasting glucose levels $\geq 5.6 \mathrm{mmol} / \mathrm{L}$ ). Overall,

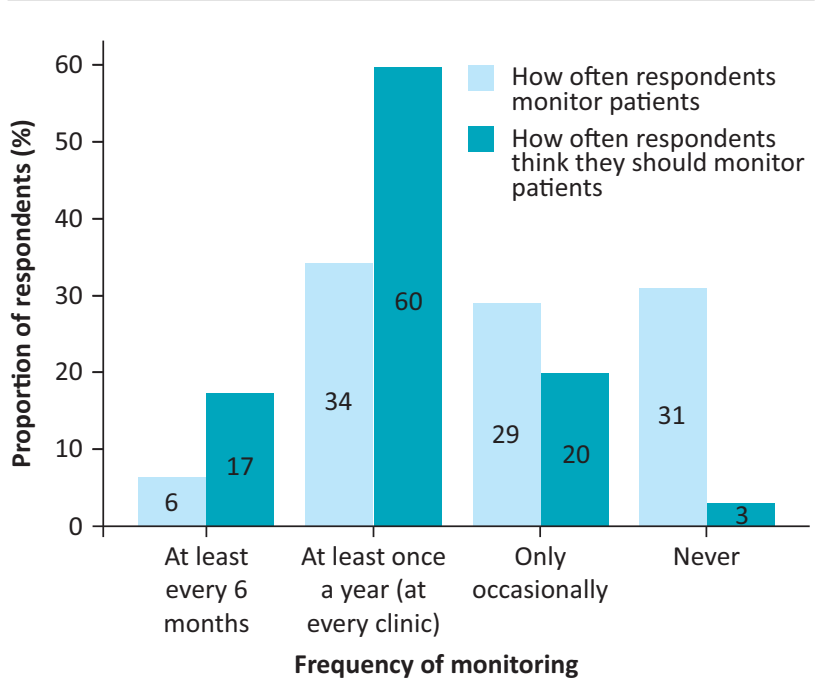

Fig 1. Frequency of monitoring risk factors for cardiovascular disease (CVD) in cancer survivors. CVD risk factors include weight, waist circumference, blood pressure, lipids and glucose. Differences between categories: $\chi^{2}=112$ ( $\left.p<0.001\right)$. Please note, the composite variables in this figure contain waist circumference as well as other factors; this results in a 'dilutional effect' and, therefore, the proportions of responders for each category of frequency of monitoring would differ between this figure and the results in Table 1 . Please refer to the methods section for details on derivation of composite variables.
14 patients $(43.8 \%)$ had at least one of these cardiometabolic risk factors.

\section{Discussion}

There exist a number of guidelines on monitoring CVD risk factors in cancer survivors with some appearing to be more comprehensive than others. ${ }^{16-20}$ For example, the recent joint guidelines from the Center for International Blood and Marrow Transplant Research and European Society for Blood and Marrow Transplantation ${ }^{16}$ recommend specific frequency of monitoring and treatment targets for individual CVD risk factors in cancer survivors following haematopoietic cell transplantation (HCT). These guidelines recommend screening at every clinic visit (at least once a year) for weight, body mass index (BMI) and BP, and yearly for waist circumference. Lipid measurement is recommended 3 months after allogenic HCT and should be repeated every 3-6 months for high-risk patients (treated with sirolimus, calcineurin inhibitors or corticosteroids) and every 5 years for standard-risk patients (males $\geq 35$ years and females $\geq 45$ years). Fasting blood glucose/ HbA1C should be checked 3 months after allogenic HCT and re-evaluated every 3-6 months for high-risk patients (treated with corticosteroids) and every 3 years for standard-risk patients. The Scottish Intercollegiate Guidelines Network guidelines ${ }^{17}$ recommend annual assessment of BP and BMI, fasting glucose, insulin and lipids every 2 years in overweight/ obese individuals and every 5 years in non-overweight/ non-obese individuals. A report from the Cardiovascular Disease Task Force of the Children's Oncology Group suggests monitoring fasting glucose and lipid profile every $3-5$ years for survivors of childhood cancer. ${ }^{18}$ Other guidelines on CVD risk monitoring of survivors of childhood malignancy recommend that, in additional to fasting glucose, lipids and HbAlC (although no specific frequency suggested), referral to endocrinologists should be considered for those with increased risk, eg bone marrow transplant recipients, especially total body irradiation or busulphan-based conditioning. ${ }^{21}$ While the precise monitoring frequency remains debatable and challenging, it is clear that monitoring, on the one hand should be tailored to the individual based on risk level (eg bone marrow transplant recipients, cranial radiotherapy, glucocorticoid treatment, growth hormone deficiency or high BMI/large waist circumference), and on the other hand should be recommended for all cancer survivors since 


\begin{tabular}{|c|c|c|c|c|}
\hline & \multicolumn{4}{|c|}{ Frequency of monitoring } \\
\hline & Three times & Twice & Once & None \\
\hline $\begin{array}{l}\text { Patients who had lipids } \\
\text { monitored }\end{array}$ & $31 \%$ & $16 \%$ & $25 \%$ & $28 \%$ \\
\hline $\begin{array}{l}\text { Patients who had } \\
\text { glucose/HbA1C } \\
\text { monitored }\end{array}$ & $16 \%$ & $19 \%$ & $34 \%$ & $31 \%$ \\
\hline
\end{tabular}

survivors of solid tumours have been shown to have similar late cardiovascular effects to survivors of haematological malignancies. ${ }^{6}$

The present study has demonstrated rather infrequent CVD risk monitoring of a group of lung cancer survivors in secondary care. Survivors of lung cancer have been shown to be among the highest risk groups for cardiovascular events ${ }^{6}$ and improvements in cancer treatment will increase the numbers of individuals at risk. Results obtained from patients' blood tests using electronic databases were consistent with the responses from healthcare providers in an interactive survey, and with results from a previous audit by Sekhar et al ${ }^{22}$ - about onethird never had risk factors measured. This lack of CVD risk monitoring is concerning as cancer survivors are known to have a high risk of CVD and related death. There appears to be low awareness of the need for monitoring CVD risk factors. Urgent action is therefore necessary to promote awareness among healthcare providers of this, particularly for long-term cancer survivors because CVD tends to manifest many years later as a consequence of the late effects of cancer treatments.

The underlying reasons for the poor CVD monitoring in cancer survivors are uncertain and likely to be multifactorial. A lack of awareness among healthcare providers of the elevated risk and of current guidelines may play a part. Cancer specialists may have been more focused on the cancer itself and tended to accept the elevated CVD risk factors if CVD does not emerge until a number of years after cancer treatments. It is therefore imperative that oncologists take responsibility for raising awareness of the risks with the patient and the GP; the responsibility for screening of CVD risk then lies with the GP (through the implementation of the treatment record summary as a component of the recovery package). ${ }^{23}$ Our survey indicates that healthcare providers actually wish to monitor CVD risk for their patients more frequently than their current practice, but we did not have information on the underlying reason for the lack of monitoring. Long-term follow-up of cancer survivors with diligent monitoring of general health - including CVD risk factors, particularly the reversible components of metabolic syndrome - is necessary in order to intervene effectively. Primary prevention has been advocated for cancer survivors. ${ }^{9}$ However, our interactive survey revealed that up to nine out of ten healthcare providers indicated that they never measured their patients' waist circumference. In contrast, when asked how often waist circumference should be checked, almost two- thirds of these specialists felt that it should be checked at least every 6-12 months. Given their high risk, CVD screening in cancer survivors should use metabolic syndrome criteria from the International Diabetes Federation ${ }^{24}$ with lower cut-off levels of waist circumference and glucose than those defined by the National Cholesterol Education Program. ${ }^{25}$

In our interactive survey, smoking habit and general CVD risk factors were only occasionally, or never, discussed by $40-60 \%$ of healthcare providers. This lack of health promotion has also been reported in a larger survey, revealing about one-third of cancer survivors did not have health promotion discussion with their healthcare providers. ${ }^{26}$

Managing treatment consequences is a key goal of new cancer strategy and solutions to this given through the implementation of the recovery package. ${ }^{23}$ Dissemination of information on CVD monitoring for cancer survivors across all healthcare disciplines is vital to ensure continuity of management of general health in the long term. The role of GPs is vital given increasing numbers of survivors are now being cared for in primary care. ${ }^{4}$ However, it has recently been shown that half of the time CVD risk is incompletely monitored in primary care. ${ }^{22}$

The strengths of this study include data sources from patients' investigations as well as direct survey of healthcare providers, which show concordant results consistent with previous studies. The present study is limited because of its small sample size and the healthcare providers surveyed were not from within the specialty of oncology. However, as previously discussed, the long-term follow-up of cancer survivors is usually performed by non-oncology specialists such as GPs and nurses. We did not have the opportunity to include physical activity, dietary habits, including alcohol intake, and adherence to treatment - which may provide important insights into the aetiology of CVD in cancer survivors. We did not have data about treatment of cardiovascular risk factors. We are not aware of any studies on detection of risk factors that automatically lead to treatment in cancer survivors but believe that any risk identified in cancer survivors should be managed at least as aggressively as that in non-cancer population. A large national survey is being planned to extend our findings, by including survivors of prostate, teratoma, breast and haematology-oncology cancers, and adult survivors of childhood cancers.

\section{Conclusions}

Despite their now well-established increased risk of CVD and related death, current monitoring of correctable CVD risk factors in cancer survivors by healthcare providers is infrequent, and does not meet recommendations from published literature. Regular monitoring and early management of CVD risk factors is required, and should be incorporated into guidelines, to prevent the elevated rates of CVD after cancer treatment, and thereby improve cancer survivorship.

\section{Conflicts of interests}

The authors have no conflicts of interest to declare.

\section{Author contributions}

AP obtained data for the audit, VP provided information of cancer survivors, MS helped collect data from the interactive survey and TSH 
conceived the idea and design of the study, performed data analysis and wrote the initial draft. All authors edited subsequent versions and approved the final version for publication.

\section{References}

1 Maddams J, Brewster D, Gavin A et al. Cancer prevalence in the United Kingdom: estimates for 2008. Br J Cancer 2009; 101:5417.

2 Maddams J, Utley M, Møller H. Projections of cancer prevalence in the United Kingdom, 2010-2040. Br J Cancer 2012;107:1195202.

3 Quaresma M, Coleman MP, Rachet B. 40-year trends in an index of survival for all cancers combined and survival adjusted for age and sex for each cancer in England and Wales, 1971-2011: a populationbased study. Lancet 2015;385:1206-18.

4 Watson EK, Rose PR, Loftus R, Devane C. Cancer survivorship: the impact on primary care. Br J Gen Pract 2011;61:e763-5.

5 Mertens AC, Liu Q, Neglia JP et al. Cause-specific late mortality among 5-year survivors of childhood cancer: The Childhood Cancer Survivor Study. J Natl Cancer Inst 2008;100:1368-79.

6 Armenian SH, Xu L, Ky B et al. Cardiovascular disease among survivors of adult-onset cancer: a community-based retrospective cohort study. J Clin Oncol 2016;34:1122-30.

7 Darby SC, McGale P, Taylor CW, Peto R. Long-term mortality from heart disease and lung cancer after radiotherapy for early breast cancer: prospective cohort study of about 300,000 women in US SEER cancer registries. Lancet Oncol 2005;6:557-65.

8 Haugnes HS, Wethal T, Aass $\mathrm{N}$ et al. Cardiovascular risk factors and morbidity in long-term survivors of testicular cancer: a 20-year follow-up study. J Clin Oncol 2010;28:4649-57.

9 Lipshultz SE, Adams MJ, Colan SD et al. Long-term cardiovascular toxicity in children, adolescents, and young adults who receive cancer therapy: pathophysiology, course, monitoring, management, prevention, and research directions: a scientific statement from the American Heart Association. Circulation 2013;128:192795.

10 Rugbjerg K, Mellemkjaer L, Boice JD et al. Cardiovascular disease in survivors of adolescent and young adult cancer: a Danish cohort study, 1943-2009. J Natl Cancer Inst 2014;106:dju110.

11 Tichelli A, Bucher C, Rovó A et al. Premature cardiovascular disease after allogeneic hematopoietic stem-cell transplantation. Blood 2007;110:3462-71.

12 Greenfield DM, Walters SJ, Coleman RE et al. Prevalence and consequences of androgen deficiency in young male cancer survivors in a controlled cross-sectional study. J Clin Endocrinol Metab 2007; 92:3476-82.

13 Greenfield DM, Blewitt A, Coleman RE et al. Evaluation of adipocytokines and traditional cardiometabolic risk factors in young male cancer survivors: an age-matched control study. Clin Endo 2016;84:296-304.

14 Han TS, Lean ME. A clinical perspective of obesity, metabolic syndrome and cardiovascular disease. JRSM Cardiovasc Dis 2016; 5:2048004016633371.
15 Greenfield D, Snowden J, Schoemans $\mathrm{H}$ et al. Metabolic syndrome is common following haematopoietic cell transplantation (HCT) and is associated with increased cardiovascular disease: an EBMT cross-sectional non-interventional study. Bone Marrow Transplant 2015;50(Suppl 1):S89-S90.

16 DeFilipp Z, Duarte RF, Snowden JA et al. Metabolic Syndrome and cardiovascular disease after hematopoietic cell transplantation: screening and preventive practice recommendations from the CIBMTR and EBMT. Biol Blood Marrow Transplant 2016;22:1493-503.

17 Scottish Intercollegiate Guidelines Network. Long term follow up of survivors of childhood cancer: a national clinical guideline. SIGN guideline No 132. Edinburgh: SIGN, 2013.

18 Shankar SM, Marina N, Hudson MM et al. Monitoring for cardiovascular disease in survivors of childhood cancer: report from the Cardiovascular Disease Task Force of the Children's Oncology Group. Pediatrics 2008;121:e387-96.

19 Bovelli D, Plataniotis G, Roila F, ESMO Guidelines Working Group. Cardiotoxicity of chemotherapeutic agents and radiotherapyrelated heart disease: ESMO Clinical Practice Guidelines. Ann Oncol 2010;21(Suppl 5):v277-82.

20 Sisler J, Chaput G, Sussman J, Ozokwelu E. Follow-up after treatment for breast cancer: Practical guide to survivorship care for family physicians. Can Fam Physician 2016;62:805-11.

21 Skinner R, Wallace WHB, Levitt GA (eds). Therapy based longterm follow-up. 2nd edn. UK Children's Cancer Study Group (UK CCSG) Late Effects Group, 2005.

22 Sekhar M, Eggenberger C, Coghlan G. How well are patients with myeloproliferative neoplasms assessed for cardiovascular risk: an audit report. Online J Clin Audits 2015;7.

23 Alberti KG, Zimmet P, Shaw J. Metabolic syndrome - a new worldwide definition. A Consensus Statement from the International Diabetes Federation. Diabet Med 2006; 23:469-80.

24 Independent Cancer Taskforce. Achieving world-class cancer outcomes: a strategy for England 2015-2020. London: Cancer Research UK, 2015. www.cancerresearchuk.org/sites/default/ files/achieving_world-class_cancer_outcomes_-_a_strategy_for_ england_2015-2020.pdf [Accessed 5 May 2017].

25 National Cholesterol Education Program (NCEP) Expert Panel on Detection, Evaluation, and Treatment of High Blood Cholesterol in Adults (Adult Treatment Panel III). Third Report of the National Cholesterol Education Program (NCEP) Expert Panel on Detection, Evaluation, and Treatment of High Blood Cholesterol in Adults (Adult Treatment Panel III) final report. Circulation 2002;106:3143-421.

26 Weaver KE, Foraker RE, Alfano CM et al. Cardiovascular risk factors among long-term survivors of breast, prostate, colorectal, and gynecologic cancers: a gap in survivorship care? J Cancer Surviv 2013;7:253-61.

Address for correspondence: Dr Thang S Han, Institute of Cardiovascular Research, Royal Holloway, University of London, Egham TW10 OEX, UK. Email: t.s.han@doctors.org.uk 